\title{
Delamination analysis of carbon fibre reinforced laminates: Evaluation of a special step drill
}

\author{
António T. Marques, Luís M. Durão, António G. Magalhães, João Francisco Silva, \\ João Manuel R.S. Tavares
}

\begin{abstract}
A B S T R A C T
Drilling of carbon fibre/epoxy laminates is usually carried out using standard drills. However, it is necessary to adapt the processes and/or tooling as the risk of delamination, or other damages, is high. These problems can affect mechanical properties of produced parts, therefore, lower reliability. In this paper four different drills - three commercial and a special step (prototype) - are compared in terms of thrust force during drilling and delamination. In order to evaluate damage, enhanced radiography is applied. The resulting images were then computational processed using a previously developed image processing and analysis platform. Results show that the prototype drill had encouraging results in terms of maximum thrust force and delamination reduction. Furthermore, it is possible to state that a correct choice of drill geometry, particularly the use of a pilot hole, a conservative cutting speed $-53 \mathrm{~m} / \mathrm{min}$ - and a low feed rate $-0.025 \mathrm{~mm} / \mathrm{rev}$ - can help to prevent delamination.
\end{abstract}

Keywords:

A. Polymer-matrix composites

B. Delamination

C. Damage mechanics

D. Non-destructive testing

Image processing and analysis

\section{Introduction}

The use, in primary structures, of fibre reinforced plastics has increased in the last decades due to their unique properties. Advantages are related with their low weight, high strength and stiffness. Although the development of these materials have been mostly related with aerospace and aeronautical applications, recent years have seen the spread of their use in many other industries, like automotive, where high production rates are required.

The use of composite laminates in dynamic structures had enabled a considerable weight reduction and, consequently, an improvement in their characteristics. Although composite components are produced to near-net shape, machining is often needed, as it turns out necessary to fulfil requirements related with tolerances or assembly needs. Machining operations in composites can be carried out using conventional machinery with adaptations. Among machining processes, drilling is one of the most frequently used to make holes for screws, rivets and bolts. However, drilling is a complex process which is characterized by the existence of extrusion by the drill chisel edge and cut by the rotating cutting lips.

As composites are neither homogeneous nor isotropic, drilling raises specific problems that can be related with subsequent damage in the region around the hole. The most frequent defects caused by drilling are delamination, fibre pull-out, interlaminar cracking or thermal damages [1,2]. These defects can affect not only the load carrying capacity of laminated parts but also reliability [3]. Rapid tool wear, as a result of material abrasiveness, can be an important factor in damage occurrence too [4] and increases the need of frequent tool changes that affects the production cycle.

When drilling of a composite part is considered, results are more dependent on fibre nature than on matrix material [5].

The importance of tool geometry in delamination reduction is evidenced by several published works on the subject. For example, Piquet et al. [6] suggested the use of a great number of cutting edges, from 3 to 6 , in order to increase the contact length between tool and part, a point angle of $118^{\circ}$ and a small rake angle. Chisel edge should be as reduced as possible. Park et al. [7] applied the helical-feed method to avoid fuzzing and delamination. The use of helical feed allow for an efficient completion of the drilling operation avoiding depth limitation. Stone and Krishnamurthy [8] studied the implementation of a neural network thrust force controller. The control scheme can minimize delamination by varying feed rate in order to control thrust force. Persson et al. [3] presented an orbital drilling method, where the hole is machined both axially and radially. This method eliminates the stationary tool centre, thus reducing the axial force, reduces the risk of tool clogging and allows for the use of one tool diameter to machine several hole diameters. Davim and Reis [9] studied the effect of cutting parameters on specific cutting pressure, 
delamination and cutting power in carbon fibre reinforced plastics. They concluded that feed rate has the greater influence on thrust force, so damage increases with feed. Tsao and Hocheng [10] analyzed the effect of a backup plate on delamination, in order to understand and explain the advantage of its use in composite laminate drilling. Results show that the use of a backup plate causes an increase in the critical thrust force, allowing for higher feed rates. In another work [11], Tsao and Hocheng conducted several practical experiences to prove the benefit of using special drill when compared to commercially available tools, like twist drill. The effect of their use on delamination was evaluated. Delamination extent was determined with the help of ultrasonic C-scan. At the end, it was possible to conclude that thrust force varies with drill geometry and with feed rate. That enables for the use of higher feed rates if adequate drill geometry is selected. More recently, Tsao and Hocheng [12] have presented the advantages of a core drill. The influence of spindle speed was relatively insignificant. Fernandes and Cook [13] investigated the thrust force during drilling with "one shot" drill bit. Their objective was to extend tool life and improve hole quality. For that, a mathematical model leading to the calculation of feed in order to keep thrust force under a critical threshold was developed. Finally, Tsao $[14,15]$ evaluated the importance of pilot hole on delamination reduction when using core drills and saw drills. Pilot hole eliminates the chisel edge effect, reducing delamination hazard. The ratio of pre-drilled hole to drill diameter must be controlled in order to drill with higher feed rate without delamination. In his experimental work, Tsao has found an optimal ratio of 0.85 for the use of the largest feed rate $-0.012 \mathrm{~mm} / \mathrm{rev}$.

Dharan and Won [16] conducted a series of machining experiments in order to propose an intelligent machining system that avoids delamination by peel-up at entrance and by push-out at exit. Such a system should be able to limit feeds when the tool contacts the plate and before drill breakthrough, avoiding delamination onset.

Recently, statistical tools had been used in the search for optimal cutting conditions or tool design. Tsao [17] applied the Taguchi method and analysis of variance to recommend a step angle of $100^{\circ}$ and a step ratio equal to $0.4 \mathrm{~mm} / \mathrm{mm}$. Both feed rate and spindle speed were conservative. Gaitonde et al. [18] developed a model based on response surface methodology for the study of the effects of cutting speed, feed rate and point angle on delamination. Results show a decrease in delamination tendency when cutting speed increases and also advise the use of low feed rates combined with adequate tool point angle. A multi-objective optimization of cutting parameters using genetic algorithms was presented by Sardiñas et al. [19].

Delamination is not an exclusive problem of carbon reinforced laminates, as there are other published works with the same objective of delamination reduction for glass fibre reinforced plastics $[20,21]$, a literature review on the theme [22] or even mediumdensity fibreboard (MDF) delamination assessment [23]. In all these works a relation between drilling parameters, tool geometry and delamination damage is studied.

As carbon fibre/epoxy laminates are opaque some of these defects are not visible in a visual inspection, so it is needed to establish non-destructive testing (NDT), like enhanced radiography, in order to determine the extension of internal damages, such as delamination. Digital images are also used to assess this type of damage after drilling [24].

Advantages in the use of composite plates are growing every day, therefore an increase in parts production and need for higher quality machining and dedicated tooling is to be expected. In this work, a different drill geometry is suggested and some comparison regarding thrust forces and delamination damage with different tools is established.

\section{Composites delamination}

\subsection{Delamination mechanism}

When delamination is concerned, it is necessary to consider two types of damage that are different in causes and effects: peel-up delamination and push-down delamination.

Peel-up delamination is a consequence of the cutting force pushing the abraded and cut materials to the flute surface. The material spirals up the drill flute before it is completely machined. A peeling force pointing upwards is introduced that tend to separate the upper lamina of the uncut portion held by the downward acting thrust force. Normally, a reduction in feed rate can reduce this delamination type.

Push-out delamination is a damage that occurs in interlaminar regions, so it depends not only on fibre nature but also on resin type and respective properties. This damage is a consequence of the compressive thrust force that the drill tip always exerts on the uncut laminate plies. There is a certain point at which the loading exceeds the interlaminar bond strength and delamination occurs. The reduction of this delamination type is the main focus of this work.

Analysis of delamination mechanisms during drilling using a Linear Elastic Fracture Mechanics - (LEFM) - approach have been developed and different models presented. The one most referred to is the Hocheng and Dharan [25] delamination model. In this model, the critical thrust force for the onset of delamination $\left(F_{c r i t}\right)$ is related with properties of the unidirectional laminate like the elastic modulus $\left(E_{1}\right)$, the Poisson ratio $\left(v_{12}\right)$, the interlaminar fracture toughness in mode I $\left(G_{I c}\right)$ and the uncut plate thickness $(h)$ :

$F_{\text {crit }}=\pi\left[\frac{8 G_{I c} E_{1} h^{3}}{3\left(1-v_{12}^{2}\right)}\right]^{1 / 2}$

A comprehensive summary of the steps towards free-delamination holes can be found in [26]. A different approach can be given by Finite Element Modeling simulation of the drilling process and delamination onset [27].

\subsection{Damage criteria}

After drilling, it is necessary to define criteria for the comparison of the delamination caused by different drilling parameters, even though they can only be applied to composites with the same stacking sequence and reinforcement fibre in nature and volume fraction. Several ratios were established for damage evaluation.

One of them is delamination Factor $\left(F_{d}\right)$ [28], a ratio between the maximum delaminated diameter $\left(D_{\max }\right)$ and hole nominal diameter $(D)$,

$F_{d}=D_{\max } / D$

In the experimental work presented, Chen [28] examined the effects of tool geometry and cutting parameters on delamination. Feed rate was identified as the most influent factor.

Tsao and Hocheng [29] evaluated the delamination factor results when using three different drills and images obtained from ultrasonic C-scan. It was found that feed rate and drill diameter had the largest influence on delamination.

This evaluation method is based on digitized damage images that must be analyzed using suitable image processing and analysis techniques [30,31].

\section{Experimental works}

\subsection{Materials and tools}

In order to perform the experimental work, a carbon fibre/ epoxy plate was fabricated from pre-preg with a stacking sequence 
of $[(0 /-45 / 90 / 45)]_{4 s}$, giving the plate quasi-isotropic properties. The pre-preg used was TEXIPREG ${ }^{\circledR}$ HS 160 REM, from SEAL. The laminate was cured under a pressure of $3 \mathrm{kPa}$ and a temperature of $140{ }^{\circ} \mathrm{C}$ for one hour in a hot plate press and air cooled afterwards, as per manufacturer indication. The final plate thickness was $4 \mathrm{~mm}$. After plate completion, coupons with $150 \mathrm{~mm}$ length and $35 \mathrm{~mm}$ width were cut.

Drilling experiments were executed in a machining centre $O K U$ MA MC-40VA. All drills are made of K20 carbide and have a diameter of $6 \mathrm{~mm}$. During drilling, thrust force was monitored with a Kistler 4782 dynamometer. The signal was transmitted via an amplifier to a PC for data acquisition - Fig. 1. Four types of drills were experimented for comparison: twist, brad, dagger and a prototype step drill - Fig. 2. Based on previous work and tool manufacturers indications five cutting speeds and three feed rates were employed - Table 1 . These cutting parameters were combined along the experimental work carried out, in a total of fifteen different setups.

Twist drill - Fig. 2a - is a standard drill with a point angle of $118^{\circ}$. In order to reduce the thrust force during drilling with this tool, pre-drilling with a $1.1 \mathrm{~mm}$ drill was used.

The brad drill - Fig. 2b - was originally designed for the cutting of wood. The main characteristic of this drill is the scythe shape of the cutting edges, tensioning the fibres in order to obtain a clean cut and a smooth machined surface.

Dagger drill - Fig. $2 \mathrm{c}$ - has a very sharp point angle $-30^{\circ}-$ and need to have enough space available at the exit side of the plate. This can be an important limitation on its use.

The special step drill - Fig. $2 \mathrm{~d}$ - was designed to reduce delamination during composites drilling. The basic design was suggested in a lecture by Dharan [32]. It has two drilling diameters -1.25 and $6 \mathrm{~mm}$ - dividing the drilling operation, and consequently the thrust force, in two stages. This division of the machining operation is entitled to cancel the chisel edge effect for the final hole drilling. Point and transition angles are $118^{\circ}$ and $135^{\circ}$, respectively. The drill tip was designed in a way to promote the initiation of the cutting action immediately after touching the plate, thus reducing the indentation effect. Like dagger drill, it needs to have available space at the exit side of the plate.

For each setup of cutting conditions, a total of five holes in separate runs were made. The thrust force was always averaged over one spindle revolution, in order to reduce signal variation that occurs during drill rotation.

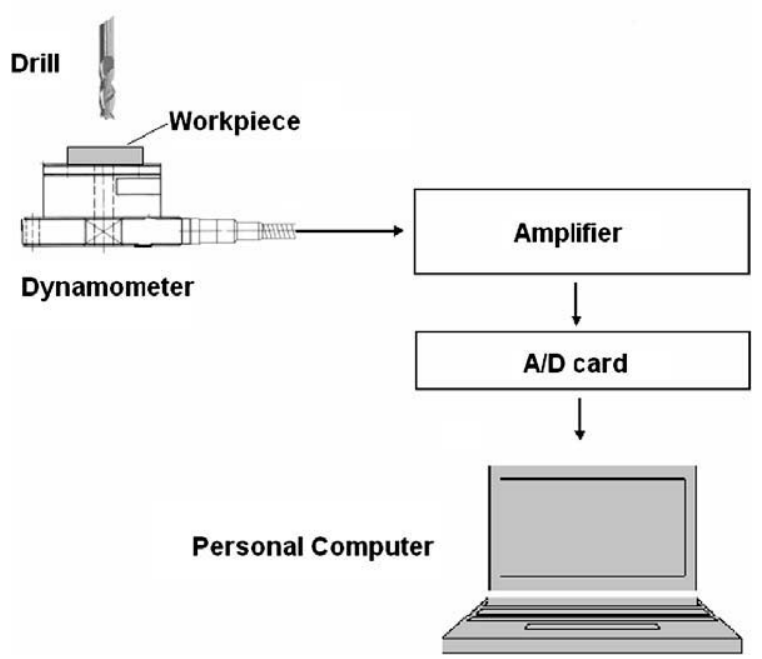

Fig. 1. Experimental setup.

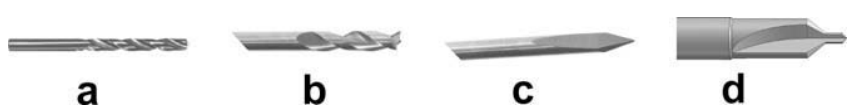

Fig. 2. Tools: (a) twist drill; (b) brad drill; (c) dagger drill and (d) special step drill.

Table 1

Relevant drilling parameters.

\begin{tabular}{lcll}
\hline Level & Cutting speed $(\mathrm{m} / \mathrm{min})$ & Spindle speed $(\mathrm{rpm})$ & Feed rate $(\mathrm{mm} / \mathrm{rev})$ \\
\hline 1 & 30 & 1600 & 0.025 \\
2 & 38 & 2000 & 0.05 \\
3 & 53 & 2800 & 0.01 \\
4 & 80 & 4200 & \\
5 & 102 & 5400 & \\
\hline
\end{tabular}

\subsection{Delamination measurement}

Delamination extension measurement is not possible by visual inspection as carbon fibre/epoxy plates are opaque. So, the plates need to be inspected by enhanced radiography. Radiography is suitable on the detection of delamination only if a contrasting fluid is used. In this work, the fluid was di-iodomethane, a radio-opaque chemical reagent. The plates were immersed for one and half hour and then cleaned and radiographed with an exposition time of $0.25 \mathrm{~s}$. The resulting images were then processed using a previously developed image processing and analysis platform $[31,33,34]$, that turned possible the use of some standard techniques of image processing and analysis in order to obtain the necessary values for the damage delamination criterion considered the damaged area and the hole diameter. This computational inspection approach has the high advantage of reducing operator dependence to measure the dimensions needed, thus increasing results reliability.

The processing sequence used is as follows:

- manual selection of interest zone of the original image, to reduce computational effort;

- smoothing of the sub-image by using a mean filter to reduce the existing noise;

- binarization of the smoothed image using an automatic algorithm $[31,33,34]$;

- elimination of noise areas presented in the binary image by the application of erosion and dilation morphologic filters [31,33,34];

- use of a region analysis algorithm to differentiate the several regions presented in the pre-processed image and obtain the desired measurements [31,33,34].

In the end, it was possible to obtain the dimensions judged as necessary in order to have a damage evaluation according to Eq. (2). Results considering any of the mentioned criteria were determined using data from this image processing and analysis pipeline. Final result from this pipeline is presented in Fig. 3.

\section{Results and discussion}

\subsection{Drilling parameters}

During drilling tests, the thrust force was continuously monitored, as previously referred. For each combination of tool geometry and cutting parameters, a total of five coupons were drilled. So, the results here presented are an average of those five runs. As delamination onset and propagation are largely dependent on the maximum value of thrust force, this was the value regarded as useful for result comparison. That force is different according to tool 

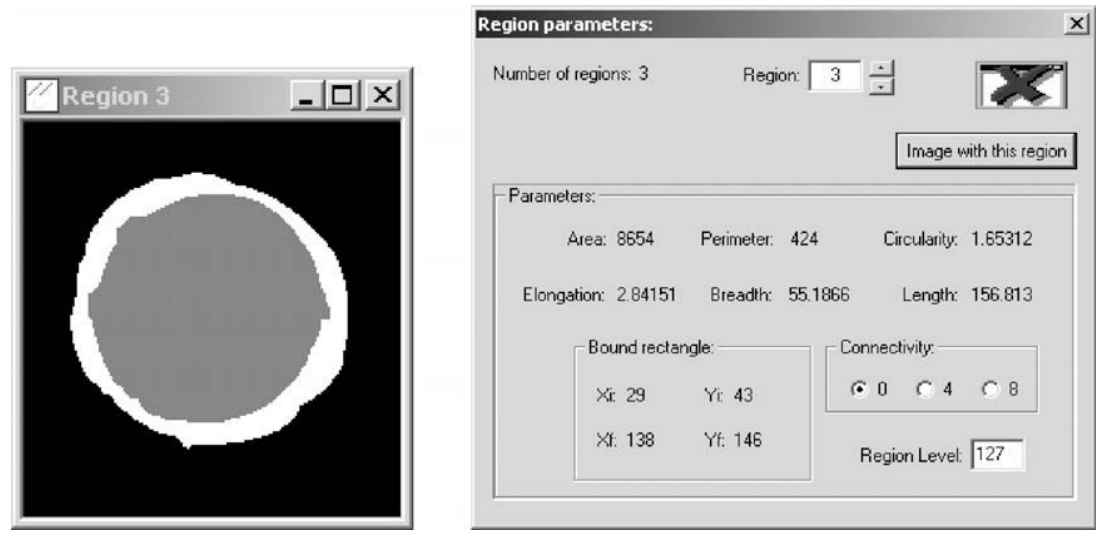

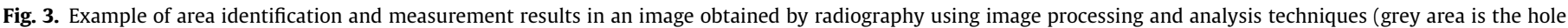
region; white area is the delaminated region).

geometry under identical cutting parameters and can be related with the chisel edge effect. Drill bit geometry is a factor for thrust force minimization, thus delamination reduction.

The first set of results here presented are concerned with parameter influence - feed rate and cutting speed - in thrust force and delamination. Feed rate is usually considered as having a major role in the indentation over the uncut thickness of the material, resulting in higher influence on delamination onset. Compared to feed rate, the cutting speed effect is slight. The evaluation of the relative contribution of each factor will not be addressed in this work.

Independently of the drill geometry or the cutting speed, a clear trend was found regarding the effect of feed rate. The finest results, either for thrust force or delamination, were always found when a low feed rate was used. Regarding the experimental setup used in this work, it is not surprising to observe that a feed of $0.025 \mathrm{~mm} /$ rev has returned the lowest delamination - Fig. 4. However, it must be remembered that a low feed rate also increases the heating of the surrounding matrix material. In some cases, it can cause matrix softening, and then thermograph techniques should be used in order to assess this risk.

Fig. 4a and $\mathrm{b}$ shows the results found for maximum thrust force and delamination factor $-F_{d}$ - for the feed rates considered. In Fig. 4a data is correlated by a 2 nd polynomial curve. It is interesting to note that a simple mathematical calculation of the minimum returns a feed rate of $0.022 \mathrm{~mm} / \mathrm{rev}$, consistent with the results here presented. Observing the results in Fig. 4b, one can say that the use of great feed rates is not recommendable in laminate drilling. Besides these results, peel-up delamination was observed when the higher feed rate $-0.1 \mathrm{~mm} / \mathrm{rev}$ - was used. This outcome leads to the need of a compromise between high production rates and damage control.

Bearing in mind that cutting speed is less significant in delamination and thrust force for laminate drilling, a similar procedure as described for feed rate was carried out. Again, it was possible to identify the best result regarding cutting speed - $53 \mathrm{~m} / \mathrm{min}$ - and by correlating data with 2nd polynomial curves, minimum thrust force is obtained for a cutting speed of $50 \mathrm{~m} / \mathrm{min}(2650 \mathrm{rpm})$, for $6 \mathrm{~mm}$ diameter drill experimented. In Fig. 5a and b, results for maximum thrust force and delamination for the different cutting speeds used are presented.

Based on these results, it seems possible to identify a "critical cutting speed" for the drilling of carbon fibre/epoxy plates. The use of speeds above or below this "critical value"' will cause an increase in thrust force and, consequently, on delamination. This result has to be confirmed with other tool diameters.
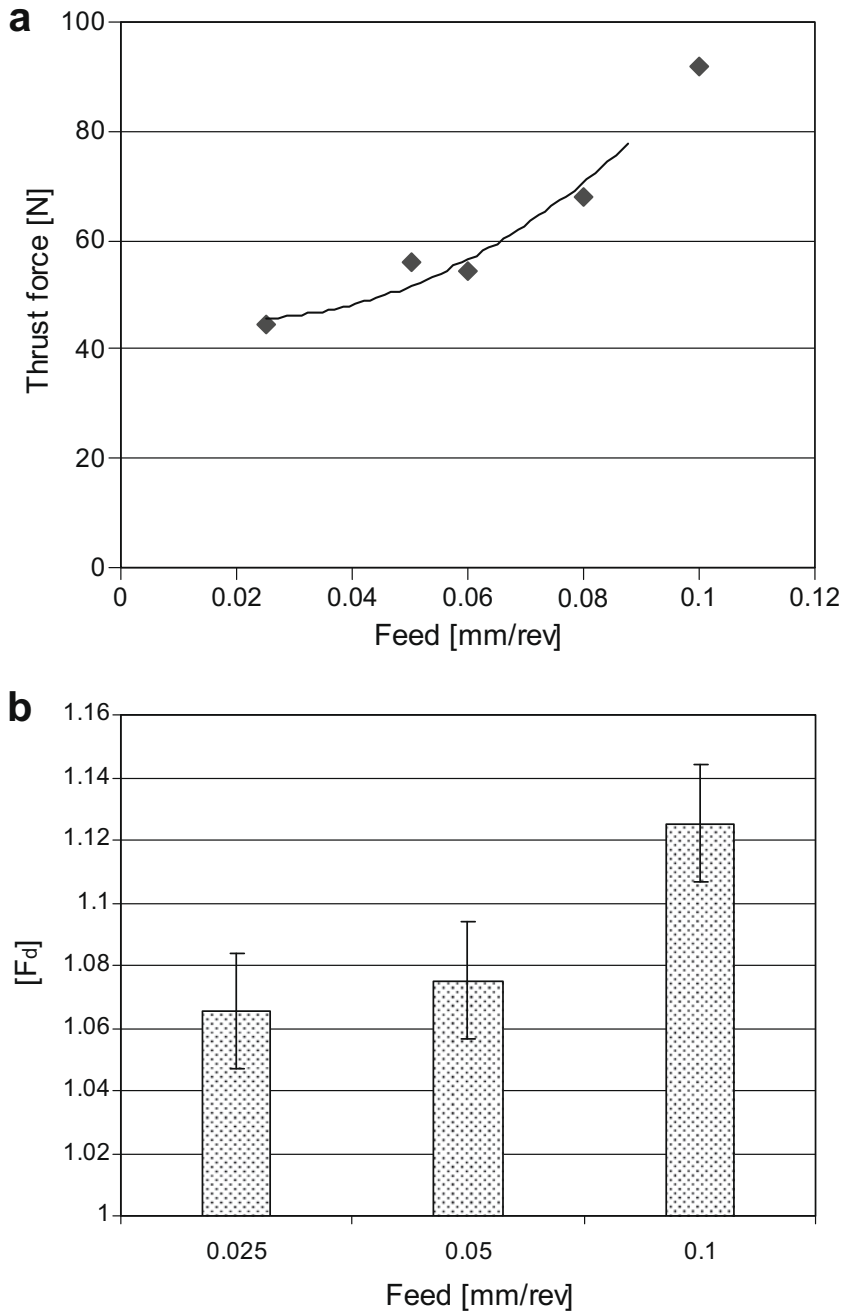

Fig. 4. Feed rate effect: (a) maximum average thrust force during drilling and (b) delamination factor $\left(F_{d}\right)$.

\subsection{Tool geometry}

Tool geometry plays a significant role in delamination reduction as the value of critical thrust force for delamination onset and propagation is dependent on drill bit geometry. Besides delamination, other issues need to be taken in account. 

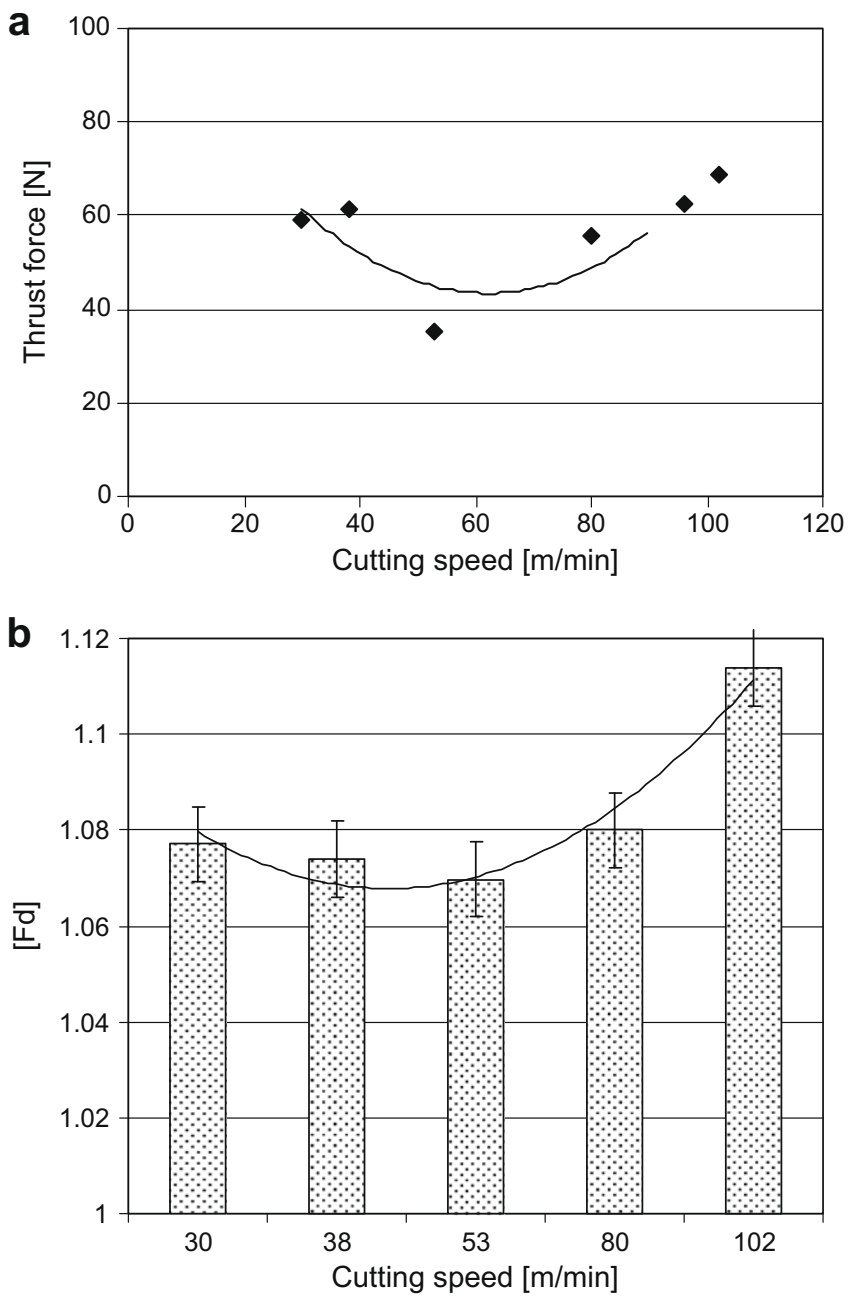

Fig. 5. Cutting speed effect: (a) maximum average thrust force during drilling and (b) delamination factor $\left(F_{d}\right)$.

Twist drill, being a common drill of universal use, tends to be less expensive and so, costs associated to tool replacement are lower. Hole quality is fair if pilot hole is used, as it was the case in this work, and there is no need for reaming. Brad drill machined surfaces have a clean cut, presenting a smooth hole surface. No advantage in the use of pre-drilling was identified when using this drill. As already referred, the main drawback for the use of dagger drills is the need of available space for drill exit at the opposite side of the plate. If that is not a problem in an experimental work, it can be the ground of some limitations in workshop area. Another problem identified during this work was the increased vibration, at the drill tip, with greater cutting speeds. This fact can be explained by the longer length of the drill. The special step drill was designed in order to have the small diameter tip as short as possible. This can be a limitation if plates of greater thickness are to be drilled, leading to the need of dedicated tooling, meaning small diameter tip length, for several ranges of plate thicknesses. The final appearance of the holes indicates the need for reaming, just like those obtained with dagger drills. The clean cut look of the machined walls was not obtained, leading to the conclusion that some changes in tool design are needed. The main objective when using this tool was the separation of the thrust force in two steps, corresponding to first and second drill diameters, reducing the maximum thrust force and, consequently, the risk of delamination onset. Only one diameter of pilot hole was used, based on previous experimental work. This feature of tool design needs to be confirmed, using different diameters for the first drilling stage.

Results considered for comparison are, again, the maximum thrust force during drilling - Fig. $6 a$ - and the measured delamination - Fig. 6b. There is an influence of drill bit geometry on thrust force during drilling. Consequently, a more favourable geometry enables the use of higher feed rates without delamination hazard.

Naturally, the variation of thrust force values when feed rates were increased was not the same for all the drills experimented. The drills that had registered less variation with feed were the dag-
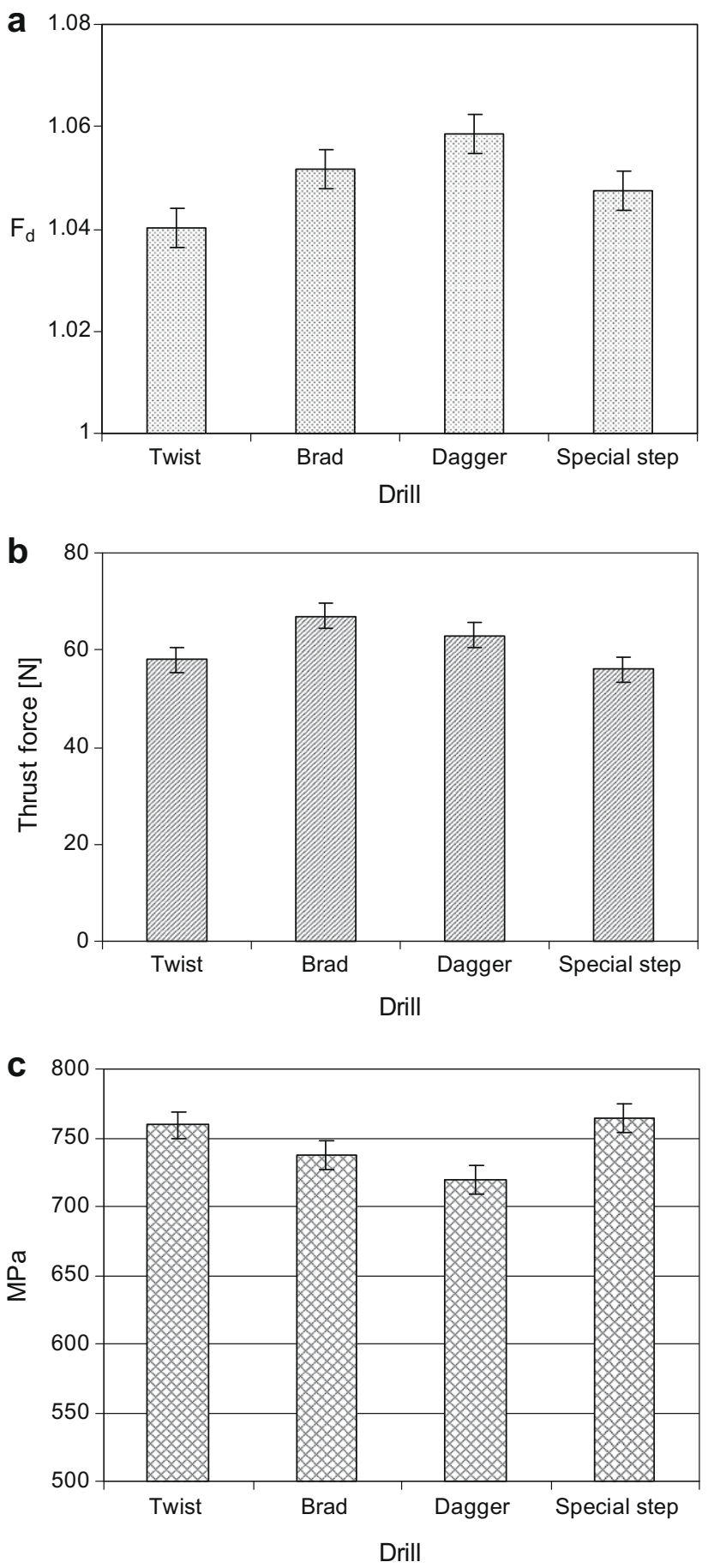

Fig. 6. Comparison of results of drill geometry: (a) maximum average thrust force during drilling; (b) delamination factor $\left(F_{d}\right)$ and (c) bearing stress test. 
ger and the brad drill. The geometry that resulted to be more affected by feed rate variation was the twist drill.

The second comparison was the delamination extension. The procedure of delamination measurement was already described in Section 3.2. It is interesting to note that the holes with less delamination were those obtained with twist drill, using a pilot hole strategy, and special step drill. These two geometries have also presented the lower values of maximum thrust force. So, tool geometry influence on delamination onset is more dependent on thrust force developed during drilling. That force is different with respect to the specific geometry of the drill and can be related mainly with the chisel edge length. However, plate properties play an important role on delamination occurrence. According to the analytical model presented in Section 2.1, critical thrust force for delamination onset is a function of mechanical properties of laminate material and uncut plate thickness. Ply orientation also plays an important part on delamination direction. The role of drill bit geometry and parameter selection is the reduction of the thrust force during drilling. The work here described is applied for $6 \mathrm{~mm}$ diameter tools and it has to be adjusted if other diameters are to be analyzed.

\subsection{Bearing test}

The main purpose of drill holes in any plate is to provide the possibility to assemble it to other parts in a structure. When in service, those parts will be subjected to efforts that will cause stress at the hole surrounding area. It is important to know what the load carrying capacity of such connection is. For that, a bearing test was used, according to ASTM D5961 [35], procedure A - double shear, single fastener. The test was executed in an INSTRON 4208 , equipped with a data acquisition system, at a speed of $2 \mathrm{~mm} / \mathrm{min}$. The test was stopped when a 30\% drop from maximum load was registered.

Results are presented in Fig. 6c, and show the average of five coupons tested with respect to the specific geometry of the drill. It is interesting to remark that the bearing stress value for the special step drill is the highest of all average values, as well as the highest individual one, not shown here. The values for the special step and twist drill with pilot hole drilling are very close. The difference to the values for the brad drill makes it believe that some influence of drilling parameters selection is present. This can explain the different bearing values registered for this test. The lowest values were obtained with the plates drilled with dagger drill. A relation between the delaminated diameter and the bearing stress of a laminate plate cannot be established with the results presented in this work.

\section{Conclusions}

Drilling of carbon fibre/epoxy laminates using different cutting parameters and four drill geometries was completed for the purpose of this work. The aim was to reduce delamination risk. Thrust forces during drilling were monitored and delamination measured with the help of enhanced radiography and image processing and analysis computational techniques. Based on the experimental work here presented it is possible to draw some conclusions.

A correct selection of cutting parameters in order to reduce thrust force and, consequently, delamination, is possible. For the experimental conditions here described, the setting of parameters that allowed for thrust force and delamination minimization was a feed rate of $0.025 \mathrm{~mm} / \mathrm{rev}$ and a cutting speed of $53 \mathrm{~m} / \mathrm{min}$. Thrust force reduction was around $12 \%$ for feed rate and $35 \%$ for cutting speed and delamination reduction potential is around $4-5 \%$ when using these combination of cutting parameters.
Besides the selection of cutting parameters, the choice of a dedicated tool for drilling fibre reinforced laminates can be useful. A drill bit geometry that reduces the indentation effect of the chisel edge is preferable. Particularly the use of a pilot hole associated to a twist drill has presented good results, enabling a $2 \%$ damage reduction when compared with the second best result obtained. The pilot hole cancels the chisel edge effect, reducing the risk of delamination. That was the basic design of the special step drill here presented. For the moment, it can be said that the special step tool does not show a definitive advantage when compared with commercial available tools, although the result of the bearing test was the highest. Future developments of this tool are needed.

Delamination damage can be evaluated by a non-destructive test like enhanced radiography. The use of image processing and analyses techniques showed to be adequate to analyze the image areas involved. With these techniques it was possible to determine and quantify the damage caused by drilling. The pipeline of image processing and analysis techniques here applied can be used for evaluation and measurement of damages in other materials.

\section{Acknowledgement}

This work is partially supported by FCT - Fundação para a Ciência e Tecnologia from Portugal, under project number PTDC/EMETME/66207/2006.

\section{References}

[1] Wern CW, Ramulu M, Shukla A. Investigation of stresses in the orthogonal cutting of fibre-reinforced plastics. Exp Mech 1994:33-41.

[2] Rao GVG, Mahajan P, Bhatnagar N. Micro-mechanical modelling of machining of FRP composites - cutting force analysis. Compos Sci Technol 2007:67:573-9.

[3] Persson E, Eriksson I, Zackrisson L. Effects of hole machining defects on strength and fatigue life of composite laminates. Composites A 1997;28:141-51.

[4] Abrate S. Machining of composite materials. In: Mallick PK, editor. Composites engineering handbook. New York: Marcel Dekker; 1997. p. 777-809.

[5] Koplev A, Lystrup Aa, Vorm T. The cutting process, chips, and cutting forces in machining CFRP. Composites 1983;14:371-6.

[6] Piquet R, Ferret B, Lachaud F, Swider P. Experimental analysis of drilling damage in thin carbon/epoxy plate using special drills. Composites A 2000;31:1107-15.

[7] Park KY, Choi JH, Lee DG. Delamination-free and high efficiency drilling of carbon fibre reinforced plastics. J Compos Mater 1995;29:1988-2002.

[8] Stone R, Krishnamurthy K. A neural network thrust force controller to minimize delamination during drilling of graphite-epoxy composites. Int J Mach Tools Manufact 1996;36:985-1003.

[9] Davim JP, Reis P. Drilling carbon fibre reinforced plastics manufactured by autoclave - experimental and statistical study. Mater Des 2003;24:315-24.

[10] Tsao CC, Hocheng $\mathrm{H}$. Effects of exit back-up on delamination in drilling composite materials using a saw drill and a core drill. Int J Mach Tools Manufact 2005;45:1261-70.

[11] Hocheng H, Tsao CC. Effects of special drill bits on drilling-induced delamination of composite materials. Int J Mach Tools Manufact 2006;46:1403-16.

[12] Tsao CC, Hocheng H. Parametric study on thrust force of core drill. J Mater Process Technol 2007;192-193:37-40.

[13] Fernandes M, Cook C. Drilling of carbon composites using a one shot drill bit. Part II: empirical modelling of maximum thrust force. Int J Mach Tools Manufact 2006;46:76-9.

[14] Tsao CC. The effect of pilot hole on delamination when core drilling composite materials. Int J Mach Tools Manufact 2006;46:1653-61.

[15] Tsao CC. Effect of pilot hole on thrust force by saw drill. Int J Mach Tools Manufact 2007;47:2172-6.

[16] Dharan CHK, Won MS. Machining parameters for an intelligent machining system for composite laminates. Int J Mach Tools Manufact 2000;39:415-26.

[17] Tsao CC. Prediction of thrust force of step drill in drilling composite material by Taguchi method and radial basis function network. Int J Adv Manufact Technol 2008;36:11-8.

[18] Gaitonde VN, Karnik SR, Rubio JC, Correia AE, Abrão AM, Davim JP. Analysis of parametric influence on delamination in high-speed drilling of carbon fiber reinforced plastic composites. J Mater Process Technol 2008;203:431-8.

[19] Sardiñas RQ, Reis P, Davim JP. Multi-objective optimization of cutting parameters for drilling laminate composite materials by using genetic algorithms. Compos Sci Technol 2006;66:3083-8.

[20] Singh I, Bhatnagar N, Viswanath J. Drilling of uni-directional glass fiber reinforced plastics: experimental and finite element study. Mater Des 2008;29:546-53. 
[21] Rubio JC, Abrão AM, Faria PE, Correia AE, Davim JP. Effects of high speed in the drilling of glass fibre reinforced plastic: evaluation of the delamination factor. Int J Mach Tools Manufact 2008;48:715-20.

[22] Abrão AM, Faria PE, Rubio JC, Reis P, Davim JP. Drilling of fiber reinforced plastics: a review. J Mater Process Technol 2007;186:1-7.

[23] Davim JP, Rubio JC, Abrão AM. Delamination assessment after drilling mediumdensity (MDF) by digital image analysis. Holzforschung 2007;61:294-300.

[24] Davim JP, Rubio JC, Abrão AM. A novel approach based on digital image analysis to evaluate the delamination factor after drilling composite laminates. Compos Sci Technol 2007;67:1939-45.

[25] Hocheng H, Dharan CKH. Delamination during drilling in composite laminates. J Eng Ind 1990;112:236-9.

[26] Hocheng $\mathrm{H}$. Tsao CC The path towards delamination-free drilling of composite materials. J Mater Process Technol 2005;167:251-64.

[27] Durão LMP, de Moura MFSF, Marques AT. Numerical prediction of delamination onset in carbon/epoxy composites drilling. Eng Fract Mech 2008;75:2767-78.

[28] Chen WC. Some experimental investigations in the drilling of carbon fibrereinforced plastic (CFRP) composite laminates. Int J Mach Tools Manufact 1997;37:1097-108.
[29] Tsao CC, Hocheng H. Effect of eccentricity of twist drill and candle stick drill on delamination in drilling composite materials. Int J Mach Tools Manufact 2005;45:125-30.

[30] Tsao CC, Hocheng H. Computerized tomography and C-scan for measuring delamination in the drilling of composite materials using various drills. Int J Mach Tools Manufact 2005;45:1282-7.

[31] Durão LM, Magalhães AG, Tavares JMRS, Marques AT. Analyzing objects in images for estimating the delamination influence on load carrying capacity of composite laminates. In: Proceedings of CompImage 2006, Coimbra, Portugal, Taylor \& Francis. p. 169-74. ISBN: 9780415433495.

[32] Dharan CKH. Lecture on composite materials machining, October 2000, INEGI, Porto.

[33] Tavares JMRS. PhD thesis, Análise de Movimento de Corpos Deformáveis usando Visão Computacional, 2000, FEUP.

[34] Tavares JMRS, Barbosa JG, Padilha AJ. Apresentação de um Banco de Desenvolvimento e Ensaio para Objectos Deformáveis. RESI - Revista Electrónica de Sistemas de Informação, vol. 1; 2002.

[35] ASTM D5961-05e1. Standard test method for bearing response of polymer matrix composite laminates. ASTM International; 2005. 